\title{
Reproduction, Functional Autonomy and Changing Experiences of Intimate Partner Violence Within Marriage in Rural India
}

\begin{abstract}
CONTEXT: The literature on intimate partner violence in resource-poor contexts relies primarily on cross-sectional studies. Because changes in women's status and empowerment are hypothesized to influence violence vulnerability, longitudinal studies are needed to determine the potential benefits and harms associated with such changes.
\end{abstract}

METHODS: Data were collected prospectively from a representative cohort of 4,749 married women in rural areas of four socially and demographically diverse states in India in 1998-1999 and 2002-2003. A multinomial regression model including social and demographic characteristics and intersurvey changes and events related to functional autonomy and reproduction was fitted to a categorical outcome measuring the absence (reference), initiation, cessation and continuation of intimate partner violence.

RESULTS: Continued freedom of movement, increased freedom of movement and continued financial autonomy between baseline and follow-up were associated with a lower risk of violence initiation rather than no violence (relative risk ratio, 0.7 for each). Having a first child was associated with lower risk of violence initiation and continuation rather than no violence ( 0.6 and 0.2 , respectively). Women who reported that their relative economic contribution to the household decreased or increased and women who experienced an unwanted pregnancy had a higher risk of violence continuation rather than no violence $(1.8,1.8$ and 1.5 , respectively). The death of a child was associated with higher risk of violence initiation rather than no violence (1.4).

CONCLUSION: Future research to inform interventions to reduce intimate partner violence should consider how changes in women's reproductive experiences and functional autonomy may be linked to changes in intimate partner violence.

International Perspectives on Sexual and Reproductive Health, 2013, 39(4):215-226, doi: 10.1363/3921513
By Christine Bourey, Rob Stephenson and Michelle J. Hindin

Christine Bourey is a master's candidate and Rob Stephenson is associate professor, both in the Hubert Department of Global Health, Rollins School of Public Health, Emory University, Atlanta, GA, USA Michelle Hindin is associate professor, Department of Population, Family and Reproductive Health, Bloomberg School of Public Health,

The Johns Hopkins University, Baltimore, MD, USA.
Male-perpetrated intimate partner violence is the most common form of violence against women, ${ }^{1,2}$ and its prevalence in South Asia is among the highest in the world..$^{3,4}$ In India, $34 \%$ of women of reproductive age reported ever having experienced intimate partner violence, ${ }^{5}$ this violence has serious health consequences for both women and children, including poor nutritional status, ${ }^{6,7}$ decreased mental ${ }^{8-10}$ and reproductive health, ${ }^{11-13}$ increased maternal and child mortality, ${ }^{14,15}$ and limited health seeking. ${ }^{16-18}$

Intimate partner violence in India occurs within the context of entrenched gender inequality. Preference for male children has led to sex-selective abortion, female infanticide, and neglect and abandonment of female children, ${ }^{19}$ between 1950 and 2012, there were an estimated 58.9 million "missing" girls. ${ }^{20}$ Gender discrimination during childhood results in differential allocation of nutrition, education and medical care, ${ }^{21-23}$ which reflects the devalued place of females in society. Nearly half (47\%) of all women aged 20-24 were married before the legal age of $18,{ }^{5}$ and as women move from their natal homes to share a home with their husband, his parents and his unmarried siblings, the protection provided by familial and community support networks is disrupted. ${ }^{24}$ Because of patrilineal inheritance practices that diminish the social and econom- ic worth of women, dowries that increase the economic burden of girls, ${ }^{25}$ and dependence on sons in old age and death, ${ }^{23}$ married women face pressure to prove their value and social worth through reproduction, and the production of sons in particular. ${ }^{24}$

Intimate partner violence is frequently viewed as a culturally acceptable form of punishment and appropriate demonstration of masculinity. Although extreme physical violence is proscribed, ${ }^{26}$ control, psychological abuse, neglect and isolation have become normalized. ${ }^{27}$ Acceptance of violence is prevalent among both men and women. In India, $51 \%$ of men and $54 \%$ of women agree that a husband is justified in beating his wife in at least one of the following circumstances: if she goes out without telling him, if she neglects the house or children, if she argues with him, if she refuses to have sex with him, if she does not cook food properly, if he suspects her of being unfaithful or if she shows disrespect for her in-laws. ${ }^{5}$ Although there is a clear association between violence, masculinity and youth, and the proportion of men who justify violence decreases with age, ${ }^{5}$ justification increases with age among women, suggesting that women may be socialized to accept and rationalize intimate partner violence.

India has received special attention within the growing 


\begin{tabular}{|c|c|c|c|c|c|c|}
\hline Characteristic & $\begin{array}{l}\text { All } \\
(\mathrm{N}=4,749)\end{array}$ & $\begin{array}{l}\text { None } \\
(\mathrm{N}=3,379)\end{array}$ & $\begin{array}{l}\text { Initiation } \\
(\mathrm{N}=781)\end{array}$ & $\begin{array}{l}\text { Cessation } \\
(\mathrm{N}=271)\end{array}$ & $\begin{array}{l}\text { Continuation } \\
(\mathrm{N}=318)\end{array}$ & Total \\
\hline \multicolumn{7}{|l|}{ State*** } \\
\hline Bihar & 40.2 & 71.5 & 15.8 & 6.1 & 6.6 & 100.0 \\
\hline Jharkhand & 13.9 & 69.2 & 21.0 & 3.3 & 6.5 & 100.0 \\
\hline Maharashtra & 17.9 & 85.9 & 9.1 & 2.2 & 2.8 & 100.0 \\
\hline Tamil Nadu & 28.1 & 62.3 & 19.8 & 8.5 & 9.4 & 100.0 \\
\hline \multicolumn{7}{|l|}{ Religion } \\
\hline Hindu & 88.2 & 70.7 & 16.4 & 6.0 & 6.9 & 100.0 \\
\hline Muslim & 8.8 & 73.8 & 16.7 & 4.1 & 5.5 & 100.0 \\
\hline Other & 3.0 & 77.5 & 16.9 & 2.1 & 3.5 & 100.0 \\
\hline \multicolumn{7}{|l|}{ Caste*** } \\
\hline General caste & 18.8 & 85.8 & 8.3 & 2.6 & 3.4 & 100.0 \\
\hline Scheduled caste/tribe & 28.8 & 62.4 & 20.2 & 7.4 & 10.0 & 100.0 \\
\hline Other backward caste & 52.4 & 70.7 & 17.3 & 5.9 & 6.1 & 100.0 \\
\hline \multicolumn{7}{|l|}{ Age at baseline ${ }^{* * *}$} \\
\hline $15-19$ & 12.9 & 71.5 & 21.2 & 2.8 & 4.6 & 100.0 \\
\hline $20-24$ & 23.4 & 69.5 & 18.5 & 4.5 & 7.6 & 100.0 \\
\hline $25-29$ & 26.2 & 69.5 & 16.8 & 6.8 & 7.0 & 100.0 \\
\hline $30-34$ & 20.8 & 71.2 & 14.7 & 6.7 & 7.4 & 100.0 \\
\hline $35-39$ & 16.7 & 75.9 & 11.5 & 6.8 & 5.8 & 100.0 \\
\hline \multicolumn{7}{|c|}{ Respondent's education $* * *$} \\
\hline No education & 61.7 & 66.8 & 18.7 & 6.5 & 8.1 & 100.0 \\
\hline Primary & 14.9 & 72.0 & 15.8 & 5.8 & 6.4 & 100.0 \\
\hline >secondary & 23.4 & 82.2 & 10.9 & 3.6 & 3.3 & 100.0 \\
\hline \multicolumn{7}{|c|}{ Husband's education*** } \\
\hline No education & 34.0 & 63.1 & 20.4 & 7.1 & 9.4 & 100.0 \\
\hline Primary & 19.0 & 68.8 & 17.2 & 5.9 & 8.2 & 100.0 \\
\hline$\geq$ secondary & 47.0 & 77.9 & 13.3 & 4.7 & 4.1 & 100.0 \\
\hline \multicolumn{7}{|c|}{ Baseline standard of living $* * *$} \\
\hline Low & 53.0 & 64.9 & 19.6 & 6.6 & 8.9 & 100.0 \\
\hline Medium & 38.7 & 75.4 & 14.5 & 5.3 & 4.8 & 100.0 \\
\hline High & 8.4 & 91.2 & 5.5 & 1.8 & 1.5 & 100.0 \\
\hline \multicolumn{7}{|l|}{ Head of household*** } \\
\hline Husband & 68.3 & 69.0 & 16.8 & 6.7 & 7.5 & 100.0 \\
\hline Mother-in-law & 24.0 & 75.6 & 15.6 & 3.6 & 5.2 & 100.0 \\
\hline Other & 7.8 & 76.2 & 16.0 & 3.8 & 4.1 & 100.0 \\
\hline
\end{tabular}

literature on intimate partner violence in resource-poor contexts. $^{28}$ Numerous studies have evaluated demographic and social variables for associations with intimate partner violence among representative and nonrepresentative samples. Studies have generally highlighted the significance of individual-level variables (e.g., socioeconomic status, ${ }^{29}$ education ${ }^{30}$ and marital age ${ }^{29}$ ) and selected experiences (e.g., spousal alcohol use, ${ }^{31}$ extramarital sex ${ }^{32}$ and witnessing violence in childhood ${ }^{32}$ ), although experiences and attitudes related to gender have also been considered. In particular, because gender inequality (seen in household power dynamics and community norms) is thought to influence women's vulnerability to intimate partner violence, attention increasingly has been granted to associations between women's status and empowerment and intimate partner violence. ${ }^{33-36}$

Studies investigating the associations between genderrelated experiences at the individual- or household-level and intimate partner violence have revealed mixed find- ings in India. For example, marital type (arranged or love), ${ }^{37}$ satisfaction with the dowry, ${ }^{37,38}$ parity, ${ }^{38,39}$ childlessness ${ }^{32,40}$ and women's employment ${ }^{41,42}$ have not been consistently associated with intimate partner violence across studies. Similarly, one study showed that women's partial economic contribution to the household was associated with greater odds of violence; ${ }^{40}$ however, another study found that full responsibility for meeting household expenses was linked to increased odds, but shared responsibility was associated with decreased odds of violence. ${ }^{43}$ Further, a study of decision-making autonomy and freedom of movement found that only selected measures, such as household wealth, tolerance of violence and decision-making autonomy, were associated with past-year intimate partner violence and that status inconsistencies, such as differences in spousal age and education, were not associated with intimate partner violence. ${ }^{44}$

Although measures of status and empowerment are hypothesized to be associated with intimate partner vio- 


\begin{tabular}{|c|c|c|c|c|c|c|}
\hline Characteristic & $\begin{array}{l}\text { All } \\
(\mathrm{N}=4,749)\end{array}$ & $\begin{array}{l}\text { None } \\
(\mathrm{N}=3,379)\end{array}$ & $\begin{array}{l}\text { Initiation } \\
(\mathrm{N}=781)\end{array}$ & $\begin{array}{l}\text { Cessation } \\
(\mathrm{N}=271)\end{array}$ & $\begin{array}{l}\text { Continuation } \\
(\mathrm{N}=318)\end{array}$ & Total \\
\hline \multicolumn{7}{|l|}{ Baseline marital duration $* * *$} \\
\hline $0-4$ years & 24.1 & 72.4 & 19.9 & 3.2 & 4.5 & 100.0 \\
\hline $5-9$ years & 23.4 & 67.2 & 18.7 & 5.9 & 8.2 & 100.0 \\
\hline$\geq 10$ years & 52.5 & 72.3 & 13.9 & 6.7 & 7.1 & 100.0 \\
\hline \multicolumn{7}{|l|}{ Age at start of current union } \\
\hline $12-14$ & 23.7 & 69.3 & 16.5 & 6.6 & 7.7 & 100.0 \\
\hline $15-17$ & 43.0 & 70.8 & 16.9 & 5.2 & 7.1 & 100.0 \\
\hline$\geq 18$ & 33.3 & 73.0 & 15.8 & 5.8 & 5.5 & 100.0 \\
\hline \multicolumn{7}{|l|}{ Spousal age difference } \\
\hline Wife older or husband $0-4$ years older & 35.5 & 70.6 & 16.7 & 5.0 & 7.6 & 100.0 \\
\hline Husband 5-9 years older & 45.4 & 70.7 & 16.5 & 6.4 & 6.5 & 100.0 \\
\hline Husband $\geq 10$ years older & 19.0 & 73.2 & 16.0 & 5.4 & 5.4 & 100.0 \\
\hline \multicolumn{7}{|l|}{ Husband's reaction to dowry*** } \\
\hline Unsatisfied & 4.0 & 45.0 & 29.1 & 7.9 & 18.0 & 100.0 \\
\hline Neutral/unsure & 12.5 & 69.6 & 15.5 & 7.6 & 7.3 & 100.0 \\
\hline Satisfied & 76.3 & 73.2 & 15.8 & 5.2 & 5.8 & 100.0 \\
\hline No dowry & 7.3 & 66.6 & 18.2 & 6.6 & 8.7 & 100.0 \\
\hline \multicolumn{7}{|l|}{ Baseline parity*** } \\
\hline 0 & 12.9 & 72.3 & 20.6 & 2.6 & 4.4 & 100.0 \\
\hline 1 & 15.9 & 67.1 & 21.0 & 4.6 & 7.3 & 100.0 \\
\hline 2 & 20.9 & 70.9 & 16.4 & 6.5 & 6.3 & 100.0 \\
\hline 3 & 20.9 & 71.8 & 14.0 & 6.2 & 8.1 & 100.0 \\
\hline$\geq 4$ & 29.5 & 72.6 & 13.9 & 6.8 & 6.7 & 100.0 \\
\hline \multicolumn{7}{|c|}{ Witnessed intimate partner violence in childhood $* * *$} \\
\hline Yes & 23.8 & 54.8 & 26.0 & 7.3 & 12.0 & 100.0 \\
\hline No & 76.2 & 76.3 & 13.5 & 5.2 & 5.0 & 100.0 \\
\hline \multicolumn{7}{|c|}{$\begin{array}{l}\text { Experienced non-intimate partner violence } \\
\text { since age } 15^{* * *}\end{array}$} \\
\hline Yes & 4.4 & 40.8 & 22.3 & 17.1 & 19.9 & 100.0 \\
\hline No & 95.6 & 72.6 & 16.1 & 5.2 & 6.1 & 100.0 \\
\hline
\end{tabular}

lence in complex and contextually varied ways, ${ }^{45}$ current data may reflect the limits of cross-sectional studies. ${ }^{1,46}$ In particular, cross-sectional data limit exploration of associations between changes in women's status and empowerment and changes in their experiences of intimate partner violence.

\section{Current Study}

As the first longitudinal study to investigate correlates of changing intimate partner violence in a representative sample of women from multiple Indian contexts, the current study was designed to describe changes in intimate partner violence prevalence within marriage and to identify changes in women's experiences associated with the initiation, cessation and continuation of intimate partner violence among women from rural areas in four Indian states, adjusting for social and demographic characteristics discussed in previous studies.

The study focuses on women's changing reproductive experiences, such as having a first child or having an unwanted pregnancy, and functional autonomy, a dimension of empowerment that captures the independence women gain through control of material and social resources. ${ }^{47}$ On one hand, noncooperative bargaining and family stress theories suggest that increasing women's functional autonomy may provide resources that support their ability to take a stand against intimate partner violence (by increasing their intrahousehold bargaining power or providing them financial autonomy that gives them options outside the home) or reduce poverty-related stress within the family that may raise the risk of intimate partner violence $^{39,48,49}$ On the other hand, theories of hegemonic masculinity and male backlash suggest that increasing functional autonomy may lead to women's transgression of prevailing social norms and men's decreased ability to influence spousal behavior, thereby increasing the risk that men will use violence to maintain the status quo. ${ }^{39,48,49}$ Developing successful interventions to prevent intimate partner violence necessitates disentangling the potential benefits granted by resources that empower or improve the status of women from the potential harms arising from status inconsistencies between spouses, threats to hegemonic masculinity and transgression of social norms that empowerment may bring. 
TABLE 2. Percentage distribution of women, by changes in intimate partner violence, according to changes in selected characteristics between baseline and follow-up

\begin{tabular}{|c|c|c|c|c|c|c|}
\hline Characteristic & All & None & Initiation & Cessation & $\begin{array}{l}\text { Continu- } \\
\text { ation }\end{array}$ & Total \\
\hline \multicolumn{7}{|c|}{ Respondent's economic contribution*** } \\
\hline No change & 85.9 & 72.7 & 15.8 & 5.6 & 5.9 & 100.0 \\
\hline Decreased & 7.8 & 58.3 & 22.3 & 6.5 & 12.9 & 100.0 \\
\hline Increased & 6.3 & 66.3 & 17.3 & 6.3 & 10.0 & 100.0 \\
\hline \multicolumn{7}{|l|}{ Employment status*** } \\
\hline None & 30.0 & 77.5 & 14.3 & 3.5 & 4.6 & 100.0 \\
\hline Decreased & 6.4 & 69.9 & 15.2 & 7.0 & 8.0 & 100.0 \\
\hline Increased & 26.7 & 69.7 & 18.3 & 5.2 & 6.8 & 100.0 \\
\hline Continued & 37.0 & 67.3 & 17.0 & 7.6 & 8.1 & 100.0 \\
\hline \multicolumn{7}{|l|}{ Financial autonomy** } \\
\hline None & 12.7 & 66.1 & 19.3 & 5.0 & 9.6 & 100.0 \\
\hline Decreased & 21.6 & 69.8 & 16.4 & 6.4 & 7.4 & 100.0 \\
\hline Increased & 16.2 & 71.0 & 17.7 & 5.3 & 6.0 & 100.0 \\
\hline Continued & 49.5 & 73.1 & 15.3 & 5.7 & 5.9 & 100.0 \\
\hline \multicolumn{7}{|l|}{ Freedom of movement $* * *$} \\
\hline None & 23.1 & 71.8 & 17.7 & 4.8 & 5.7 & 100.0 \\
\hline Decreased & 5.5 & 15.3 & 1.5 & 6.9 & 76.3 & 100.0 \\
\hline Increased & 38.6 & 14.5 & 6.0 & 6.4 & 73.1 & 100.0 \\
\hline Continued & 32.9 & 18.0 & 6.7 & 7.7 & 67.6 & 100.0 \\
\hline \multicolumn{7}{|l|}{ Childlessness*** } \\
\hline No change & 90.7 & 70.7 & 16.1 & 6.0 & 7.2 & 100.0 \\
\hline Had a child & 9.3 & 75.9 & 19.4 & 2.5 & 2.3 & 100.0 \\
\hline \multicolumn{7}{|l|}{ Contraceptive use $\mathrm{e}^{* * *}$} \\
\hline None & 49.2 & 67.7 & 19.0 & 5.9 & 7.4 & 100.0 \\
\hline Adoption & 17.5 & 73.4 & 15.3 & 5.3 & 6.0 & 100.0 \\
\hline Cessation & 1.5 & 71.4 & 14.3 & 5.7 & 8.6 & 100.0 \\
\hline Continued & 31.9 & 75.2 & 13.2 & 5.6 & 6.0 & 100.0 \\
\hline \multicolumn{7}{|l|}{ Decision-making authority } \\
\hline Limited & 28.4 & 72.3 & 16.2 & 5.6 & 5.9 & 100.0 \\
\hline Decreased & 18.4 & 72.6 & 15.6 & 5.1 & 6.8 & 100.0 \\
\hline Increased & 26.6 & 69.6 & 16.9 & 6.1 & 7.4 & 100.0 \\
\hline Continued & 26.6 & 70.5 & 16.8 & 5.9 & 6.8 & 100.0 \\
\hline \multicolumn{7}{|l|}{$\begin{array}{l}\text { Justification of intimate } \\
\text { partner violence* }\end{array}$} \\
\hline None & 13.7 & 74.4 & 15.7 & 4.2 & 5.7 & 100.0 \\
\hline Decreased & 16.2 & 72.0 & 14.5 & 5.9 & 7.7 & 100.0 \\
\hline Increased & 48.5 & 69.6 & 17.8 & 5.5 & 7.0 & 100.0 \\
\hline Continued & 21.7 & 71.9 & 15.3 & 7.0 & 5.8 & 100.0 \\
\hline \multicolumn{7}{|c|}{$\begin{array}{l}\text { Relative economic condition } \\
\text { of household } * * *\end{array}$} \\
\hline No change & 46.4 & 73.2 & 16.4 & 5.0 & 5.4 & 100.0 \\
\hline Worsened & 26.2 & 63.2 & 18.9 & 8.0 & 10.0 & 100.0 \\
\hline Improved & 27.5 & 14.2 & 4.8 & 5.8 & 75.2 & 100.0 \\
\hline \multicolumn{7}{|c|}{$\begin{array}{l}\text { Relative economic condition of house- } \\
\text { hold, by baseline standard of living**** }\end{array}$} \\
\hline Low, no change & 25.4 & 67.8 & 19.7 & 5.2 & 7.3 & 100.0 \\
\hline Low, worsened & 15.9 & 59.4 & 20.1 & 8.6 & 12.0 & 100.0 \\
\hline Low, improved & 11.7 & 66.1 & 18.9 & 6.8 & 8.3 & 100.0 \\
\hline Medium/high, no change & 21.0 & 79.8 & 12.5 & 4.7 & 3.0 & 100.0 \\
\hline Medium/high, worsened & 10.3 & 69.0 & 17.1 & 6.9 & 6.9 & 100.0 \\
\hline Medium/high, improved & 15.7 & 82.1 & 10.7 & 3.2 & 4.0 & 100.0 \\
\hline
\end{tabular}

${ }^{*} p<.05 .{ }^{* *} p<.01 .{ }^{* * *} p \leq .001$. Notes: Intimate partner violence was measured for the 12 months preceding baseline and follow-up. Percentages may not add to 100.0 because of rounding.

\section{METHODS}

\section{Study Setting}

Four culturally and economically distinct Indian states are included in this analysis: Bihar, Jharkhand, Maharashtra and Tamil Nadu. These states were chosen to represent di- verse cultural, contraceptive and programmatic contexts, and consequently vary across a range of socioeconomic indicators and sociocultural norms related to the status of women. ${ }^{50}$ A principal demarcation exists between the eastern states of Bihar and Jharkhand (formerly one state) and the western and southern states of Maharashtra and Tamil Nadu. Bihar and Jharkhand are among the less-developed states in the nation, with $57-66 \%$ of households having a low standard of living; in addition, the two states account for only $2-3 \%$ of the gross national product. ${ }^{50}$ Maharashtra and Tamil Nadu are among India's more developed states, with $45 \%$ of households having a low standard of living; these states account for $7-13 \%$ of the gross national product. $^{50}$

Women in Bihar and Jharkhand have a younger median age at marriage (14.9 years) than women in Maharashtra and Tamil Nadu (16.4 and 18.7 years), ${ }^{51}$ and lower proportions of women in Bihar and Jharkhand report ever having used a modern contraceptive method (20-26\% in Bihar and Jharkhand vs. $51-64 \%$ in Maharashtra and Tamil Nadu). Differences also persist in women's ability to participate in at least one household decision, such as the decision to seek health care, make major household purchases, make daily household purchases, or visit family or relatives (73-81\% in Bihar and Jharkhand vs. 87-92\% in Maharashtra and Tamil Nadu), and a smaller proportion of women in Bihar and Jharkhand than in Maharashtra and Tamil Nadu report participating in paid employment within the previous 12 months (47-50\% in Bihar and Jharkhand vs. 70-90\% in Maharashtra and Tamil Nadu). ${ }^{5}$ Although differences in domestic violence across these states are small, lifetime physical violence was reported by $33-53 \%$ of women of reproductive age in Bihar and Jharkhand and by 29-39\% in Maharashtra and Tamil Nadu. ${ }^{5}$

\section{Data Source}

The data come from two linked data sets: the 1998-1999 National Family Health Survey (NFHS-2) and a prospective survey conducted in 2002-2003. The NFHS-2 was the second national survey; the sample represented $99 \%$ of the population and included approximately 90,000 evermarried reproductive-age women (15-49 years). ${ }^{51}$ Overall response rates for sampled women were high (96\%), ranging from $94 \%$ to $100 \%$ in the states included in this study. ${ }^{51}$ The International Institute for Population Sciences in Mumbai and the Johns Hopkins Bloomberg School of Public Health in Baltimore, MD, USA, conducted the prospective survey in 2002-2003 to explore family planning service quality, subsequent contraceptive use and the predictive validity of stated fertility intentions. ${ }^{50}$ The sampling frame for the follow-up study included married women who were the usual residents of rural households in Bihar, Jharkhand, Maharashtra and Tamil Nadu, and who were interviewed in the original study. The sample was restricted to rural areas because it was expected that gaining complete information on family planning services 
would be more feasible in these areas given the complexity of service provision in urban India, and only married women were interviewed because premarital sex is strongly proscribed in India, which limits the ability to accurately measure fertility and contraceptive behavior among unmarried women. Only women aged 15-39 at baseline were included because older women (40-44 years) were not of reproductive age at follow-up. High rates of reinterview were achieved in all four states, ranging from $76 \%$ in Maharashtra to 94\% in Tamil Nadu. With the exception of lower baseline contraceptive use and domestic violence prevalence in Bihar and Tamil Nadu, ${ }^{50}$ the characteristics of the reinterviewed and nonreinterviewed samples were generally similar, indicating no significant selectivity in the reinterviewed sample.

Trained female interviewers administered both surveys, either within a private area of the home or outside the home. Among the 6,437 women who completed the follow-up survey, the domestic violence module was administered to only 6,303, the youngest woman in households with multiple eligible respondents, in keeping with World Health Organization protocols for intimate partner violence research. ${ }^{52}$ To reduce known misclassification, 713 women (11\%) who reported intimate partner violence in the NFHS-2 but reported never having experienced intimate partner violence in the follow-up survey were excluded. An additional 841 women (13\%) were excluded because of missing data, yielding a final sample size of 4,749 women.

\section{Measures}

-Dependent variable. A categorical variable describing changes in the report of intimate partner violence was created from the NFHS- 2 and follow-up survey. In the NFHS-2, a woman who responded yes to the stem question, "Since you completed 15 years of age, have you been beaten or mistreated physically by any person," identified her husband as a perpetrator and reported an occurrence of violence in the past 12 months was classified as having experienced intimate partner violence. In the followup survey, a woman was classified as having experienced intimate partner violence if she reported that her husband had perpetrated any of the following acts at least once in the past 12 months: pushed, pulled or held her down; hit her with his fist or did something that could cause injury; kicked or dragged her; tried to strangle or burn her; or attacked her with a knife, gun or other weapon. The variable had four categories: no intimate partner violence (no report of intimate partner violence on either survey), intimate partner violence initiation (no report of violence at baseline, but report of intimate partner violence at followup), intimate partner violence cessation (report of intimate partner violence at baseline, but not at follow-up), and intimate partner violence continuation (report of intimate partner violence in both surveys).

- Control and independent variables. A comprehensive list of characteristics and experiences hypothesized or previ-
TABLE 3. Percentage distribution of women, by changes in intimate partner violence, according to reproductive events experienced between baseline and follow-up

\begin{tabular}{|c|c|c|c|c|c|c|}
\hline Event & All & None & Initiation & Cessation & Continuation & Total \\
\hline \multicolumn{7}{|l|}{ Child death** } \\
\hline Yes & 13.4 & 65.2 & 20.9 & 6.4 & 7.5 & 100.0 \\
\hline No & 86.6 & 72.1 & 15.8 & 5.6 & 6.6 & 100.0 \\
\hline \multicolumn{7}{|c|}{ Pregnancy unwanted by respondent** } \\
\hline Yes & 12.3 & 65.8 & 17.5 & 7.5 & 9.3 & 100.0 \\
\hline No & 87.7 & 71.9 & 16.3 & 5.5 & 6.3 & 100.0 \\
\hline \multicolumn{7}{|c|}{ Pregnancy unwanted by husband* } \\
\hline Yes & 11.3 & 65.9 & 17.8 & 7.8 & 8.5 & 100.0 \\
\hline No & 88.7 & 71.8 & 16.3 & 5.4 & 6.5 & 100.0 \\
\hline \multicolumn{7}{|c|}{ Pregnancy termination* } \\
\hline Yes & 7.4 & 65.7 & 21.5 & 4.8 & 7.9 & 100.0 \\
\hline No & 92.6 & 71.6 & 16.0 & 5.8 & 6.6 & 100.0 \\
\hline \multicolumn{7}{|l|}{ Birth*** } \\
\hline Yes & 45.3 & 68.5 & 18.9 & 5.6 & 7.0 & 100.0 \\
\hline No & 54.7 & 73.4 & 14.4 & 5.8 & 6.4 & 100.0 \\
\hline \multicolumn{7}{|c|}{ Unfulfilled gender preference* } \\
\hline None & 87.8 & 71.8 & 15.8 & 5.7 & 6.7 & 100.0 \\
\hline Preference for boy & 10.1 & 67.0 & 21.6 & 5.7 & 5.9 & 100.0 \\
\hline Preference for girl & 2.2 & 64.1 & 18.5 & 6.8 & 10.7 & 100.0 \\
\hline
\end{tabular}

ously demonstrated to be associated with intimate partner violence was developed from the data. Social and demographic characteristics were evaluated as control variables, and included caste, age, respondents' and husbands' educational level, and standard of living, marriage duration and parity at baseline. Intersurvey changes and events related to functional autonomy and reproduction, hypothesized to be triggers for changing experiences of violence, were evaluated as independent variables. Financial autonomy was measured by asking the women if they were allowed to set aside some money (yes or no). Freedom of movement was measured by asking the women "Do you need permission to go to the market? Visit relatives or friends?" Response options were "yes," "no" or "not allowed to go." The effect of childlessness captured the potential protection conferred by having a first child, rather than the potential risk imposed by remaining childless, because of its collinearity with parity when the latter was explored. Household decision making measured participation in decisions to seek health care, purchase jewelry, and visit friends or relatives. Women were assigned a score for each question ( $2=\mathrm{de}-$ cided independently or jointly with their husbands, $1=$ decided with other family members and $0=$ their husbands or others family members decided), the scores were summed and a dichotomous variable was created (range, 0-6; 2 or less=limited authority, 3 or more=increased authority). Attitudes toward intimate partner violence captured agreement that a husband is justified in beating his wife if she neglects household responsibilities or if he suspects she is unfaithful; a composite measure was generated from the two questions and scored categorically $(0=$ does not agree with either reason, $1=$ agrees with either reason, $2=$ agrees 


\begin{tabular}{|c|c|c|c|}
\hline Characteristic or experience & $\begin{array}{l}\text { Initiation vs. } \\
\text { no violence }\end{array}$ & $\begin{array}{l}\text { Cessation vs. } \\
\text { no violence }\end{array}$ & $\begin{array}{l}\text { Continuation vs. } \\
\text { no violence }\end{array}$ \\
\hline \multicolumn{4}{|l|}{ BACKGROUND CHARACTERISTICS } \\
\hline \multicolumn{4}{|l|}{ State } \\
\hline Bihar (ref) & 1.00 & 1.00 & 1.00 \\
\hline Jharkhand & $1.30(1.01-1.68)$ & $0.53(0.32-0.86)$ & $0.87(0.58-1.30)$ \\
\hline Maharashtra & $0.58(0.42-0.82)$ & $0.25(0.14-0.45)$ & $0.28(0.16-0.50)$ \\
\hline Tamil Nadu & $1.56(1.15-2.10)$ & $1.77(1.12-2.78)$ & $1.71(1.10-2.66)$ \\
\hline \multicolumn{4}{|l|}{ Caste } \\
\hline General caste (ref) & 1.00 & 1.00 & 1.00 \\
\hline Scheduled caste/tribe & $1.53(1.11-2.11)$ & $1.46(0.85-2.51)$ & $1.27(0.78-2.06)$ \\
\hline Other backward caste & $1.43(1.06-1.94)$ & $1.13(0.67-1.91)$ & $0.88(0.55-1.42)$ \\
\hline \multicolumn{4}{|l|}{ Respondent's education } \\
\hline No education (ref) & 1.00 & 1.00 & 1.00 \\
\hline Primary & $0.86(0.66-1.12)$ & $0.82(0.54-1.23)$ & $0.80(0.54-1.18)$ \\
\hline zsecondary & $0.69(0.52-0.91)$ & $0.67(0.43-1.04)$ & $0.63(0.41-0.98)$ \\
\hline \multicolumn{4}{|l|}{ Husband's education } \\
\hline No education (ref) & 1.00 & 1.00 & 1.00 \\
\hline Primary & $0.79(0.62-1.01)$ & $0.78(0.53-1.14)$ & $0.80(0.57-1.12)$ \\
\hline zsecondary & $0.80(0.65-0.99)$ & $0.93(0.66-1.30)$ & $0.64(0.46-0.88)$ \\
\hline \multicolumn{4}{|l|}{ Baseline standard of living } \\
\hline Low (ref) & 1.00 & 1.00 & 1.00 \\
\hline Medium & $0.81(0.67-0.98)$ & $0.97(0.71-1.31)$ & $0.71(0.53-0.96)$ \\
\hline High & $0.34(0.21-0.55)$ & $0.33(0.14-0.76)$ & $0.26(0.11-0.63)$ \\
\hline \multicolumn{4}{|l|}{ Age at start of current union } \\
\hline $12-14$ (ref) & 1.00 & 1.00 & 1.00 \\
\hline $15-17$ & $0.93(0.75-1.15)$ & $0.77(0.55-1.07)$ & $0.85(0.63-1.16)$ \\
\hline$\geq 18$ & $0.85(0.67-1.09)$ & $0.83(0.57-1.21)$ & $0.67(0.46-0.95)$ \\
\hline \multicolumn{4}{|l|}{ Spousal age difference } \\
\hline Wife older or husband 0-4 years older (ref) & 1.00 & 1.00 & 1.00 \\
\hline Husband 5-9 years older & $1.09(0.91-1.31)$ & $1.36(1.01-1.83)$ & $0.90(0.69-1.18)$ \\
\hline Husband $\geq 10$ years older & $0.88(0.70-1.12)$ & $0.86(0.59-1.27)$ & $0.57(0.39-0.82)$ \\
\hline \multicolumn{4}{|l|}{ Husband's reaction to dowry } \\
\hline Unsatisfied (ref) & 1.00 & 1.00 & 1.00 \\
\hline Neutral/unsure & $0.39(0.25-0.60)$ & $0.62(0.32-1.20)$ & $0.31(0.18-0.54)$ \\
\hline Satisfied & $0.37(0.25-0.53)$ & $0.45(0.25-0.81)$ & $0.23(0.15-0.37)$ \\
\hline No dowry & $0.47(0.29-0.75)$ & $0.66(0.32-1.36)$ & $0.35(0.19-0.63)$ \\
\hline \multicolumn{4}{|l|}{ Baseline parity } \\
\hline 0 (ref) & 1.00 & 1.00 & 1.00 \\
\hline 1 & $0.80(0.52-1.22)$ & $1.59(0.59-4.24)$ & $0.65(0.35-1.21)$ \\
\hline 2 & $0.59(0.38-0.90)$ & $1.99(0.77-5.19)$ & $0.52(0.28-0.96)$ \\
\hline 3 & $0.52(0.34-0.80)$ & $2.09(0.80-5.44)$ & $0.72(0.39-1.32)$ \\
\hline$\geq 4$ & $0.42(0.27-0.64)$ & $1.84(0.71-4.76)$ & $0.44(0.24-0.81)$ \\
\hline
\end{tabular}

with both reasons).

Child death during the intersurvey period was calculated as the difference in the number of children who had ever died at baseline and the number who had ever died at follow-up, by gender, to capture the potential for son preference to mediate intimate partner violence risk. A prospective measure of gender preference was used to capture fulfillment of baseline preference for the birth of a son or a daughter during the intersurvey period. Because no differential effect was found by gender, the variables were simplified to binary measures for birth and death during the intersurvey period in the final model. Unwanted pregnancy was measured prospectively to reduce postbirth rationalization and subsequent misclassification; ${ }^{12}$ a woman who then indicated she or her husband did not want to have any more children at baseline and who had a child during the intersurvey period was categorized as having a pregnancy unwanted by the respondent or a pregnancy unwanted by the husband, respectively.

\section{Analyses}

Bivariate analyses were used to estimate crude associations between each independent variable and the categorical outcome. A multinomial regression model was fitted to the categorical outcome; no experience of intimate partner violence was used as the reference category. Three sets of variables were included: stable background characteristics, changes occurring between baseline and follow-up, and reproductive events occurring during the intersurvey period. When collinearity occurred or intervening variables ob- 


\begin{tabular}{|c|c|c|c|}
\hline Characteristic or experience & $\begin{array}{l}\text { Initiation vs. } \\
\text { no violence }\end{array}$ & $\begin{array}{l}\text { Cessation vs. } \\
\text { no violence }\end{array}$ & $\begin{array}{l}\text { Continuation vs. } \\
\text { no violence }\end{array}$ \\
\hline \multicolumn{4}{|c|}{ BACKGROUND CHARACTERISTICS } \\
\hline \multicolumn{4}{|c|}{ Witnessed intimate partner violence in childhood } \\
\hline No (ref) & 1.00 & 1.00 & 1.00 \\
\hline Yes & $2.35(1.96-2.82)$ & $1.55(1.15-2.07)$ & $2.70(2.07-3.51)$ \\
\hline \multicolumn{4}{|c|}{ Experienced non-intimate partner violence since age 15} \\
\hline No (ref) & 1.00 & 1.00 & 1.00 \\
\hline Yes & $2.09(1.43-3.07)$ & $5.33(3.45-8.24)$ & $5.07(3.32-7.74)$ \\
\hline \multicolumn{4}{|c|}{ CHANGES BETWEEN SURVEYS } \\
\hline \multicolumn{4}{|c|}{ Respondent's economic contribution } \\
\hline No change (ref) & 1.00 & 1.00 & 1.00 \\
\hline Decreased & $1.27(0.93-1.73)$ & $0.73(0.45-1.19)$ & $1.76(1.17-2.66)$ \\
\hline Increased & $1.11(0.78-1.56)$ & $0.98(0.58-1.65)$ & $1.75(1.12-2.75)$ \\
\hline \multicolumn{4}{|l|}{ Employment status } \\
\hline None (ref) & 1.00 & 1.00 & 1.00 \\
\hline Decreased & $0.75(0.51-1.09)$ & $1.47(0.83-2.60)$ & $0.93(0.54-1.59)$ \\
\hline Increased & $1.05(0.83-1.33)$ & $1.45(0.96-2.19)$ & $0.97(0.67-1.42)$ \\
\hline Continued & $1.09(0.85-1.40)$ & $2.28(1.53-3.41)$ & $1.13(0.77-1.65)$ \\
\hline \multicolumn{4}{|l|}{ Financial autonomy } \\
\hline None (ref) & 1.00 & 1.00 & 1.00 \\
\hline Decreased & $0.81(0.61-1.08)$ & $1.20(0.74-1.92)$ & $0.67(0.45-1.00)^{*}$ \\
\hline Increased & $0.83(0.62-1.12)$ & $0.91(0.55-1.52)$ & $0.52(0.34-0.81)$ \\
\hline Continued & $0.72(0.55-0.93)$ & $0.92(0.59-1.44)$ & $0.46(0.32-0.66)$ \\
\hline \multicolumn{4}{|l|}{ Freedom of movement } \\
\hline None (ref) & 1.00 & 1.00 & 1.00 \\
\hline Decreased & $0.72(0.48-1.08)$ & $0.27(0.09-0.77)$ & $1.16(0.64-2.10)$ \\
\hline Increased & $0.71(0.57-0.90)$ & $0.86(0.60-1.25)$ & $0.95(0.67-1.36)$ \\
\hline Continued & $0.72(0.55-0.96)$ & $0.71(0.45-1.13)$ & $0.82(0.53-1.27)$ \\
\hline \multicolumn{4}{|l|}{ Childlessness } \\
\hline No change (ref) & 1.00 & 1.00 & 1.00 \\
\hline Had a child & $0.60(0.38-0.95)$ & $0.79(0.26-2.39)$ & $0.16(0.07-0.38)$ \\
\hline \multicolumn{4}{|l|}{ EVENTS BETWEEN SURVEYS } \\
\hline \multicolumn{4}{|l|}{ Child death } \\
\hline No (ref) & 1.00 & 1.00 & 1.00 \\
\hline Yes & $1.43(1.13-1.79)$ & $1.19(0.82-1.73)$ & $1.15(0.81-1.63)$ \\
\hline \multicolumn{4}{|c|}{ Pregnancy unwanted by respondent } \\
\hline No (ref) & 1.00 & 1.00 & 1.00 \\
\hline Yes & $1.21(0.94-1.56)$ & $1.35(0.94-1.94)$ & $1.47(1.04-2.07)$ \\
\hline
\end{tabular}

scured relationships, variables with the greatest predictive value were chosen for the final model. All analyses were performed using STATA 11.0.

\section{RESULTS}

Overall, most women were Hindu (88\%), and $81 \%$ belonged to a scheduled caste or tribe or other backward caste (Table 1, page 216). Some 63\% of the sample was aged 29 years or younger and $62 \%$ had received no education; by contrast, $47 \%$ of respondents' husbands had at least a secondary education. Fifty-three percent of the women had a low standard of living at baseline. More than three-quarters of the women reported that their husbands were satisfied with their dowry. Half of the women in the sample had three or more children at baseline. Onequarter $(24 \%)$ reported witnessing intimate partner violence in childhood; $4 \%$ reported experiencing non- intimate partner violence since age 15 . Seventy-two percent of respondents reported no experience of intimate partner violence at either time point; $16 \%$ reported intimate partner violence only at follow-up, $6 \%$ reported intimate partner violence only at baseline, and $7 \%$ reported intimate partner violence at both baseline and follow-up. Reported intimate partner violence increased from 13\% at baseline ( $6 \%$ cessation, $7 \%$ continuation) to $23 \%$ at follow-up ( $16 \%$ initiation, $7 \%$ continuation), an increase of $77 \%$. The distribution of intimate partner violence status differed significantly for all social and demographic characteristics except religion, age at the start of the respondent's current marriage and spousal age difference.

About $14 \%$ of the sample reported a change in their relative household economic contribution between baseline and follow-up; 33\% reported a change in employment status (Table 2, page 218). Changes in financial autonomy 
and freedom of movement were reported by $38 \%$ and $44 \%$ of the women, respectively. Nine percent had a first child. About half of the sample (49\%) did not use contraceptives; $18 \%$ began using contraceptives, 32\% continued using contraceptives and 2\% stopped using contraceptives between surveys. Attitudes toward intimate partner violence changed for $65 \%$ of the women, with $49 \%$ reporting more agreement with common justifications for spousal abuse from baseline to follow-up. Some $46 \%$ of the women reported the same household economic conditions at baseline and follow-up, while $26 \%$ reported at follow-up that their conditions had worsened and 28\% reported that they had improved. One-quarter (25\%) of those with a low standard of living at baseline and $21 \%$ of those with medium or high standards of living at baseline reported no change in their economic condition at follow-up; however, $16 \%$ of women with a low standard of living at baseline and $10 \%$ of women with medium or high standards of living at baseline reported a decline in their economic condition at follow-up. Improvements in economic conditions were reported at follow-up by $12 \%$ of women with a low baseline standard of living and 16\% of women with medium or high standards of living at baseline. Only decisionmaking authority was not associated with a statistically different distribution of intimate partner violence status.

Between surveys, $13 \%$ of respondents experienced the death of a child (Table 3, page 219). Almost one-quarter had a pregnancy that they (12\%) or their husband did not want (11\%). The birth of a child was experienced by $45 \%$ of the sample. In bivariate analyses, the distribution of intimate partner violence status varied for these measures, as well as for pregnancy termination and unfulfilled gender preference.

\section{Regression Analysis}

Key control variables included previous exposure to violence: Witnessing intimate partner violence in childhood and experiencing non-intimate partner violence were associated with a higher risk of intimate partner violence initiation (relative risk ratio, 2.4 and 2.1, respectively), cessation (1.6 and 5.3, respectively) and continuation (2.7 and 5.1, respectively) rather than no intimate partner violence (Table 4, pages 220-221). Women who had at least a secondary education and those whose husband had at least a secondary education had a lower risk of intimate partner violence initiation (0.7 and 0.8 , respectively) and continuation ( 0.6 for each) rather than no intimate partner violence. In addition, compared with women whose husband was unsatisfied with their dowry, women whose husband was satisfied with the dowry had lower risk of intimate partner violence initiation (0.4), cessation (0.5) and continuation (0.2), and women whose husband was neutral and those who did not bring a dowry had a lower risk of intimate partner violence initiation ( 0.4 and 0.5 , respectively) and continuation (0.3 and 0.4 , respectively).

- Intimate partner violence initiation. Among intersurvey changes and events, continued financial autonomy, contin- ued freedom of movement and increased freedom of movement were associated with a lower risk of intimate partner violence initiation (relative risk ratio, 0.7 for each) rather than no intimate partner violence. Having a first child also was associated with lower risk of intimate partner violence initiation (0.6) rather than no intimate partner violence. The death of a child was associated with higher risk of intimate partner violence initiation rather than no intimate partner violence (1.4)

- Intimate partner violence cessation. Women for whom freedom of movement decreased had lower risk of intimate partner violence cessation rather than no intimate partner violence (relative risk ratio, 0.3). Being employed at both time points was associated with higher risk of intimate partner violence cessation rather than no intimate partner violence (2.3).

- Intimate partner violence continuation. Decreased, increased and continued financial autonomy were associated with a lower risk of intimate partner violence continuation rather than no intimate partner violence (relative risk ratio, 0.7, 0.5 and 0.5, respectively), as was having a first child (0.2). In contrast, women with a decreased or increased relative economic contribution to the household, and women who had a pregnancy they did not want, had a higher risk of intimate partner violence continuation rather than no intimate partner violence (1.8, 1.8 and 1.5 , respectively).

\section{DISCUSSION}

Our study has several notable findings. First, prevalence estimates revealed a $77 \%$ increase in intimate partner violence prevalence from baseline to follow-up. These results were unexpected and suggest the complexity of intimate partner violence measurement. One possible explanation is that increased prevalence reflects an absolute increase in intimate partner violence. At the societal level, theory suggests that intimate partner violence may increase during periods of social change, when gains in functional autonomy outpace the transformation of social norms. ${ }^{45}$ This explanation was offered by Simister and Mehta in their analysis of crime statistics and household surveys, which found a dramatic increase in intimate partner violence prevalence between 1998 and 2006. ${ }^{53}$ However, intimate partner violence is measured by self-report, and increased prevalence may reflect increased disclosure because of changes in social desirability bias or the perceived therapeutic value of disclosure during face-to-face interviews. ${ }^{54}$ Maturation effects, or the effect of time on the likelihood of experiencing the outcome (in this case, the effect of relationship duration on the likelihood of violence), also may explain differences in intimate partner violence experience over time, although they are less likely in the present study because exposure time was equalized by measurement of intimate partner violence within the past year at both time points. Understanding both instability in intimate partner violence reporting and population trends in India is an important goal for future research.

Complex associations emerged among intersurvey 
experiences and events and shifting intimate partner violence; variables associated with higher risk for initiation generally differed from variables associated with higher risk for continuation or lower risk for cessation. Although there is limited empirical evidence to evaluate these findings, studies from resource-rich contexts offer preliminary support for different correlates for intimate partner violence initiation and continuation. ${ }^{55,56}$ Because changing experiences were found to be significantly associated with shifting intimate partner violence when traditional social and demographic risk factors were controlled for, future research should aim to better understand the potential for changing experiences to be novel targets of intimate partner violence prevention interventions.

\section{Reproductive Experiences}

Analyzing findings across changes in past-year intimate partner violence at the two time periods revealed consistent results regarding reproductive experiences. Adverse reproductive experiences (e.g., child death or unwanted pregnancy) were associated with increased risk of intimate partner violence initiation or continuation, while positive reproductive experiences (e.g., having a first child) were associated with lower risk of initiation and continuation of violence. According to sociocultural analyses of Indian society, women's status and power within the family and community are tied to reproduction; ${ }^{24}$ framing the findings in this way suggests a need to develop alternate, socially sanctioned opportunities for women to gain status, capital and power. However, causality cannot be determined from this analysis, and these reproductive experiences may be correlates or consequences of intimate partner violencesexual violence often accompanies physical violence, ${ }^{1}$ increasing risk for unwanted pregnancy; controlling behaviors frequently accompany intimate partner violence, limiting family planning ${ }^{12,57}$ and health care utilization; ${ }^{16,18}$ and physical violence may affect children directly, increasing risk for injury and death.

\section{Functional Autonomy}

Associations between increased functional autonomy and intimate partner violence varied across measures. Consistent with noncooperative bargaining and family stress theories, which suggest that increased functional autonomy may be associated with lower intimate partner violence risk, increased freedom of movement was associated with lower risk for initiation of intimate partner violence, and increased financial autonomy was associated with a lower risk for continuation of violence. However, consistent with theories of hegemonic masculinity and male backlash, which suggest that men may react to increased functional autonomy by using violence as a mechanism to maintain male power and control, increased relative economic contributions were associated with a higher risk of intimate partner violence continuation.

Rather than favoring divergent theoretical interpretations, however, these associations may be explained by differences in the dimensions of functional autonomy captured by study variables, including varied temporal or causal associations and associations with unmeasured contextual variables (e.g., dyadic experiences). For example, increases in the woman's relative economic contribution may be associated with a higher risk of intimate partner violence because these increases challenge household power structures economically or symbolically (e.g., when increased access to resources grants women more independence in decision making or challenges prevailing norms and values) or because concurrent experiences increase risk (e.g., when a woman seeks employment to mitigate poverty exacerbated by spousal employment instability). Similarly, increased freedom of movement may be granted in the context of permissive familial norms and limited social repercussions or as a privilege of increased status, reflecting potentially meaningful maturation effects.

Statistical or temporal associations cannot establish causality, and investigation of the dyadic, community and social contexts in which the changes occurred were limited by the data available. These measures should be incorporated into future longitudinal research to consider how these changes may shape and interact with changing functional autonomy and intimate partner violence experience. Such research may assist theory development, in part by addressing persistent questions about the relevance of bargaining models in the absence of viable strategies to end abusive relationships and the relative significance of patriarchal social norms and hegemonic masculinity in the Indian context.

\section{Limitations}

This study is subject to several limitations. First, data from $25 \%$ of respondents were excluded from the analysis, reflecting both nonresponse and known classification error. Although instability in intimate partner violence reporting is poorly understood, analysis of excluded and included women suggested no significant differences across major social and demographic indicators or outcome categories. Second, although widespread acceptance of intimate partner violence may reduce stigma and social desirability bias, ${ }^{12}$ intimate partner violence may be subject to underreporting, and differential reporting caused by changed measures cannot be ruled out or disentangled from the effects of social desirability bias and perceived therapeutic value of disclosure. Third, data were collected in 1998-1999 and 2002-2003. Although Simister and Mehta suggest gender norms are becoming more equitable, ${ }^{53}$ their analyses did not stratify urban and rural areas, and Dreze and Sen argue that widespread social and demographic change has not occurred, suggesting instead that development in India has been an "unprecedented success" in terms of economic growth, but an "extraordinary failure" in terms of improvements in social indicators. ${ }^{58}$

The survey design limited the ability to capture complex patterns of change and order temporal experiences precisely. Further research is needed to determine how changes 
in functional autonomy and reproductive experiences are related to changes in intimate partner violence and how dyadic and community experiences shape and interact with changing individual experiences and intimate partner violence. It also must be underscored that functional autonomy is not equivalent to empowerment ("an expansion in the range of potential choices available" $45(\mathrm{p} .85)$ that enable outcomes to reflect women's values), but a dimension of it. ${ }^{45}$ Differences in functional autonomy among women reflect not only differences linked to common experiences of subordination but also individual preferences and internal constraints, ${ }^{45}$ an aggregate understanding of which may be useful for intervention development.

\section{Conclusion}

Despite increased attention to intimate partner violence in India, there remains a critical need to better understand the implications of changes in women's status and empowerment for intimate partner violence risk, including disentangling the potential benefits and harms of increased status and empowerment for women. This study contributes to the existing literature by confirming substantial dynamism in intimate partner violence experiences in marital relationships, suggesting differences in the variables associated with violence initiation and continuation, and demonstrating associations between changes in women's lives and intimate partner violence experiences. Consistent associations between reproductive experiences and changing intimate partner violence suggest the need to research these relationships further, as developing alternate, socially sanctioned opportunities for women to gain status and power may be important if reproductive experiences precede changes in intimate partner violence. Similarly, mixed associations between measures of functional autonomy and intimate partner violence highlight the need for further research that captures the dyadic and social contexts in which intimate partner violence occurs, particularly because these contexts may affect the outcomes of interventions intended to empower women.

Despite unclear population trends, these findings and contemporary analyses indicate a need to further expand the evidence base for interventions addressing intimate partner violence within marital relationships in India. Longitudinal analyses that extend these findings through more precise temporal ordering, multilevel analyses and broader population samples are important to this endeavor.

\section{REFERENCES}

1. World Health Organization (WHO), Violence by intimate partners, in: Krug EG et al., eds., World Report on Violence and Health, Geneva: WHO, 2002, pp. 87-122.

2. WHO, Global and Regional Estimates of Violence Against Women, Geneva: WHO, 2013, <http://www.who.int/reproductivehealth/ publications/violence/9789241564625/en/index.html>, accessed Nov. 5, 2013

3. Hindin MJ, Kishor S and Ansara DL, Intimate Partner Violence Among Couples in 10 DHS Countries: Predictors and Health Outcomes, Calverton, MD, USA: Macro International, 2008.
4. Garcia-Moreno $C$ et al., Prevalence of intimate partner violence: findings from the WHO multi-country study on women's health and domestic violence, Lancet, 2006, 368(9543):1260-1269.

5. International Institute for Population Sciences (IIPS) and Macro International, National Family Health Survey (NFHS-3), 2005-06: India, Mumbai: IIPS, 2007.

6. Ackerson LK and Subramanian SV, Domestic violence and chronic malnutrition among women and children in India, American Journal of Epidemiology, 2008, 167(10):1188-1196.

7. Chowdhary $\mathrm{N}$ and Patel V, The effect of spousal violence on women's health: findings from the Stree Arogya Shodh in Goa, India, Journal of Postgraduate Medicine, 2008, 54(4):306-312.

8. Chandra PS, Satyanarayana VA and Carey MP, Women reporting intimate partner violence in India: associations with PTSD and depressive symptoms, Archives of Women's Mental Health, 2009, 12(4):203-209.

9. Kumar $\mathrm{S}$ et al., Domestic violence and its mental health correlates in Indian women, British Journal of Psychiatry, 2005, 187:62-67.

10. Shidhaye R and Patel V, Association of socio-economic, gender and health factors with common mental disorders in women a population-based study of 5,703 married rural women in India, International Journal of Epidemiology, 2010, 39(6):1510-1521.

11. Decker MR et al., Intimate partner violence functions as both a risk marker and risk factor for women's HIV infection: findings from Indian husband-wife dyads, Journal of Acquired Immune Deficiency Syndromes, 2009, 51(5):593-600.

12. Stephenson R et al., Domestic violence, contraceptive use and unwanted pregnancy in rural India, Studies in Family Planning, 2008, 39(3):177-186

13. Sudha S, Morrison S and Zhu L, Violence against women, symptom reporting and treatment for reproductive tract infections in Kerala state, Southern India, Health Care for Women International, 2007, 28(3):268-284

14. Ganatra BR, Coyaji KJ and Rao VN, Too far, too little, too late: a community-based case-control study of maternal mortality in rural west Maharashtra, India, Bulletin of the World Health Organization, 1998, 76(6):591-598.

15. Koenig MA et al., Domestic violence and early childhood mortality in rural India: evidence from prospective data, International Journal of Epidemiology, 2010, 39(3):825-833.

16. Koski AD, Stephenson R and Koenig MR, Physical violence by partner during pregnancy and use of prenatal care in rural India Journal of Health, Population and Nutrition, 2011, 29(3):245-254.

17. Sabarwal $\mathrm{S}$ et al., Association between maternal intimate partner violence victimization and childhood immunization in India, Journal of Tropical Pediatrics, 2012, 58(2):107-113.

18. Sudha S and Morrison S, Marital violence and women's reproductive health care in Uttar Pradesh, India, Women's Health Issues, 2011, 21(3):214-221.

19. Hesketh T, Selecting sex: the effect of preferring sons, Early Human Development, 2011, 87(11):759-761.

20. Chaudhuri S, Female infant mortality disadvantage in India: a regional analysis, Review of Radical Political Economics, 2012, 44(3):321-326.

21. Arnold F, Choe MK and Roy TK, Son preference, the family-building process and child mortality in India, Population Studies, 1998, 52(3):301-315

22. Corsi DJ et al., Gender inequity and age-appropriate immunization coverage in India from 1992 to 2006, BMC International Health and Human Rights, 2009, 9(Suppl. 1):S3

23. Chaudhuri S, The desire for sons and excess fertility: a household-level analysis of parity progression in India, International Perspectives on Sexual and Reproductive Health, 2012, 38(4):178-186.

24. Jejeebhoy SJ, Wife-beating in rural India: a husband's right? Evidence from survey data, Economic and Political Weekly, 1998 , 33(15):855-862. 
25. Bloch F and Rao V, Terror as a bargaining instrument: a case study of dowry violence in rural India, American Economic Review, 2002, 92(4):1029-1043.

26. Go VF et al., Crossing the threshold: engendered definitions of socially acceptable domestic violence in Chennai, India, Culture, Health \& Sexuality, 2003, 5(5):393-408.

27. Kaur R and Garg S, Domestic violence against women: a qualitative study in a rural community, Asia-Pacific Journal of Public Health, 2010, 22(2):242-251.

28. Sharma BR, Social etiology of violence against women in India, Social Science Journal, 2005, 42(3):375-389.

29. Ackerson LK and Subramanian SV, State gender inequality, socioeconomic status and intimate partner violence in India: a multilevel analysis, Australian Journal of Social Issues, 2008, 43(1):81-102.

30. Ackerson LK et al., Effects of individual and proximate educational context on intimate partner violence: a population-based study of women in India, American Journal of Public Health, 2008, 98(3):507-514.

31. Jeyaseelan L et al., World studies of abuse in the family environment-risk factors for physical intimate partner violence, Injury Control and Safety Promotion, 2004, 11(2):117-124.

32. Koenig MA et al., Individual and contextual determinants of domestic violence in North India, American Journal of Public Health, 2006, 96(1):132-138

33. Boyle $\mathrm{MH}$, Community influences on intimate partner violence in India: women's education, attitudes towards mistreatment and standards of living, Social Science \& Medicine, 2009, 69(5):691-697.

34. Blanc AK et al., The effect of power in sexual relationships on sexual and reproductive health: an examination of the evidence, Studies in Family Planning, 2001, 32(3):189-213.

35. Heise LL, Violence against women: an integrated, ecological framework, Violence Against Women, 1998, 4(3):262-290.

36. Vyas S and Watts C, How does economic empowerment affect women's risk of intimate partner violence in low and middle income countries? A systematic review of published evidence, Journal of International Development, 2009, 21(5):577-602.

37. Rocca $\mathrm{CH}$ et al., Challenging assumptions about women's empowerment: social and economic resources and domestic violence among young married women in urban South India, International Journal of Epidemiology, 2009, 38(2):577-585.

38. Babu BV and Kar SK, Domestic violence in Eastern India: factors associated with victimization and perpetration, Public Health, 2010, 124(3):136-148

39. Krishnan S et al., Do changes in spousal employment status lead to domestic violence? Insights from a prospective study in Bangalore, India, Social Science E Medicine, 2010, 70(1):136-143.

40. Madhivanan P, Krupp K and Reingold A, Correlates of intimate partner physical violence among young reproductive age women in Mysore, India, Asia-Pacific Journal of Public Health, 2011, doi: 10.1177/1010539511426474, accessed July 19, 2013.

41. Dalal K, Does economic empowerment protect women from intimate partner violence? Journal of Injury and Violence Research, 2011, 3(1):35-44.

42. Babu BV and Kar SK, Domestic violence against women in eastern India: a population-based study on prevalence and related issues, BMC Public Health, 2009, 9:129.

43. Krishnan S, Gender, caste and economic inequalities and marital violence in rural South India, Health Care for Women International, 2005, 26(1):87-99.

44. Mogford E, When status hurts: dimensions of women's status and domestic abuse in rural Northern India, Violence Against Women, 2011, 17(7):835-857.

45. Kabeer N, Money Can't Buy Me Love? Re-evaluating Gender, Credit and Empowerment in Rural Bangladesh, Sussex, UK: Institute for Development Studies, University of Sussex, 1998, <http://www.ids. ac.uk/idspublication/money-can-t-buy-me-love-re-evaluating-gender- credit-and-empowerment-in-rural-bangladesh>, accessed Apr. 12 2013.

46. Jewkes R, Intimate partner violence: causes and prevention, Lancet, 2002, 359(9315):1423-1429.

47. Jejeebhoy S, Women's autonomy in rural India: its dimensions, determinants and the influence of context, in: Presser HB and Sen G, eds., Women's Empowerment and Demographic Processes: Moving Beyond Cairo, Oxford, UK: Oxford University Press, 2000.

48. Agarwal B, "Bargaining" and gender relations: within and beyond the household, Feminist Economics, 1997, 3(1):1-51.

49. Macmillan R and Gartner R, When she brings home the bacon: labor-force participation and the risk of spousal violence against women, Journal of Marriage and the Family, 1999, 61(4):947-958.

50. IIPS and Johns Hopkins University, Final Report of the 2003 NFHS-2 Four-State Follow-up Survey, Mumbai: IIPS, 2005.

51. IIPS and ORC Macro, National Family Health Survey (NFHS-2), 1998-99: India, Mumbai: IIPS, 2000

52. WHO, Putting Women First: Ethical and Safety Recommendations for Research on Domestic Violence Against Women, Geneva: WHO, 2001.

53. Simister J and Mehta PS, Gender-based violence in India: longterm trends, Journal of Interpersonal Violence, 2010, 25(9):1594-1611.

54. Rathod SD et al., ACASI and face-to-face interviews yield inconsistent estimates of domestic violence among women in India: the Samata Health Study 2005-2009, Journal of Interpersonal Violence, 2011, 26(12):2437-2456.

55. Crowne SS et al., Risk factors for intimate partner violence initiation and persistence among high psychosocial risk Asian and Pacific Islander women in intact relationships, Women's Health Issues, 2012 22(2):el81-el88

56. Coker AL et al., Intimate partner violence incidence and continuation in a primary care screening program, American Journal of Epidemiology, 2007, 165(7):821-827.

57. Stephenson R, Koenig MA and Ahmed S, Domestic violence and contraceptive adoption in Uttar Pradesh, India, Studies in Family Planning, 2006, 37(2):75-86.

58. Dreze J and Sen A, Putting growth in its place: it has to be but a means to development, not an end in itself, Outlook, 2011, <http:/ www.outlookindia.com/article.aspx?278843>, accessed July 19, 2013.

\section{RESUMEN}

Contexto: La bibliografía sobre violencia de pareja en contextos de bajos recursos se centra principalmente en estudios transversales. Puesto que los cambios en la situación y en el empoderamiento de las mujeres influyen supuestamente en su vulnerabilidad a la violencia, es necesario acometer estudios longitudinales para determinar los beneficios y daños potenciales asociados con dichos cambios.

Métodos: El estudio se basa en datos recolectados prospectivamente a partir de una cohorte representativa de $4.749 \mathrm{mu}$ jeres casadas y residentes en áreas rurales de cuatro estados social y demográficamente diversos de la India, en los años 1998-1999 y 2002-2003. A partir de esos datos se ajustó un modelo de regresión multinomial (que incluye características sociales y demográficas, los cambios ocurridos entre las encuestas y los eventos relacionados con la autonomía funcional y la reproducción) a un resultado categórico que mide la ausencia (referencia), el inicio, el cese y la continuación de la violencia de pareja.

Resultados: Entre la situación inicial y la situación en el momento del seguimiento, la libertad continuada de movi- 
mientos, una mayor libertad de movimientos y la autonomía financiera continuada se asociaron más con un menor riesgo de inicio de violencia que con la ausencia de violencia (cociente de riesgo relativo de 0,7 en cada uno de los casos). Tener un primer hijo se asoció más con un menor riesgo de iniciación y continuación de la violencia que con la ausencia de violencia (0,6 y 0,2 respectivamente). Las mujeres que reportaron un aumento o una disminución de su contribución económica relativa a la familia, así como las mujeres que experimentaron un embarazo no deseado, tuvieron un riesgo mayor de continuación de la violencia que de ausencia de violencia (1,8 para los dos primeros casos; 1,5 para el último). La muerte de un hijo se asoció más con un mayor riesgo de inicio de la violencia que con la ausencia de violencia $(1,4)$.

Conclusión: Las investigaciones e intervenciones futuras para reducir la violencia de pareja deben considerar las posibles relaciones entre los cambios que se dan en las experiencias reproductivas y la autonomía funcional de las mujeres y los cambios que se dan en la violencia de pareja.

\section{RÉSUMÉ}

Contexte: La littérature relative à la violence conjugale dans les contextes à faibles ressources repose principalement sur des études transversales. L'hypothèse étant que la variation du statut et de l'autonomisation de la femme influencent la vulnérabilité à la violence, des études longitudinales sont nécessaires pour déterminer les avantages et les inconvénients potentiels associés à cette variation.
Méthodes: Les données ont été collectées de manière prospective dans une cohorte représentative de 4.749 femmes mariées dans les milieux ruraux de quatre états socialement et démographiquement divers d'Inde en 1998-1999 et 2002-2003. Un modèle de régression multinomial tenant compte des caractéristiques sociodémographiques et des changements et événements d'autonomie fonctionnelle et de procréation inter-enquêtes a été ajusté à un résultat catégoriel mesurant l'absence (référence), le début, la cessation et la poursuite de la violence conjugale.

Résultats: La liberté de mouvement continue, l'accroissement de la liberté de mouvement et l'autonomie financière continue entre la base et le suivi sont associés à un moindre risque de début de violence plutôt qu'à son absence (rapport de risque relatif, 0,7 pour chacun). Avoir un premier enfant est associé à un moindre risque de début et de poursuite de violence plutôt qu'à son absence (0,6 et 0,2, respectivement). Les femmes ayant déclaré une diminution ou un accroissement de leur contribution économique relative au ménage et celles ayant eu une grossesse non désirée présentent un risque supérieur de poursuite plutôt que d'absence de violence (1,8, 1,8 et 1,5, respectivement). La mort d'un enfant est associée à un risque supérieur de début plutôt que d'absence de violence $(1,4)$.

Conclusion: La recherche future destinée aux interventions de lutte contre la violence conjugale devrait considérer la manière dont la variation des expériences génésiques et d'autonomie fonctionnelle des femmes peut être liée aux variations de cette violence.

Author contact: christine.bourey@gmail.com 